\title{
EDUCAÇÃO FÍSICA, PRÁTICA PEDAGÓGICA E NÃO-DIRETIVIDADE: A PRODUCC̃̃O DE UMA "PERIFERIA DA QUADRA"
}

Rogério Cruz Oliveira*

Jocimar Daolio**

RESUMO: Em aulas de Educação Física na escola é comum a não participação de alguns alunos nas atividades corporais, o que faz com que estes alunos fiquem à margem da aula, o que estamos chamando de "periferia da quadra". Considerando que este não é algo dado ou natural, mas produzido pelo contexto escolar, o objetivo desse estudo é analisar a relação entre a prática pedagógica em Educação Física e a produção da "periferia da quadra". Trata-se de uma etnografia desenvolvida com uma turma de $7^{\circ}$ ano do ensino fundamental de uma escola pública, tendo como instrumentos de coleta de dados a entrevista semi-estruturada e a observação. Concluímos que a prática pedagógica do professor de Educação Física, predominantemente não-diretiva, teve íntima relação com a produção de uma "periferia da quadra". Assim, as aulas de Educação Física, configuradas como tempo e espaço de maior liberdade aos alunos, acabaram restritas ao conformismo.

Palavras-chave: Educação física; prática pedagógica; método de ensino.

* Doutor em Educação Física pela Faculdade de Educação Física da Universidade Estadual de Campinas (UNICAMP) e Professor Adjunto da Universidade Federal de São Paulo (UNIFESP) Campus Baixada Santista. E-mail: rogerio.unifesp@gmail.com

* * Doutor em Educação Física pela Universidade Estadual de Campinas (UNICAMP) e Professor Titular da Faculdade de Educação Física da Universidade Estadual de Campinas (UNICAMP).

E-mail: jocimar.daolio@gmail.com 


\section{PHYSICAL EDUCATION, PEDAGOGICAL PRACTICE AND NON-DIRECTIVITY: THE PRODUCTION OF A COURT "PERIPHERY"}

ABSTRACT: In Physical Education classes is common that some students don't engage in body practices. Thus we have students at the margins of classes - at the "court's" periphery. Considering that isn't something natural, but it produced by school context, the objective of this study is to analyze the relationship between teaching practice in Physical Education and the production of the court's "periphery" (students at the margins of Physical Education classes). This is an ethnography survey conducted with a group of 7 th grade students at a public school, with semi-structured interviews and observation as instruments to collect data. We conclude that the Physical Education teacher's pedagogical practice, predominantly non-directive, had a close relationship with the production of a court "periphery". Thus, the physical education classes, configured as a time and space of more freedom to students, ended up restricted to conformity. keywords: Physical Education; pedagogical practice; method of teaching.

\section{INTRODUÇÃO}

A Educação Física (EF), ao longo de sua história, consolidou sua imagem/status na escola como uma disciplina menos rígida do currículo, um momento de sair da rotina da sala de aula e/ou até mesmo apoio pedagógico para outras disciplinas (BRACHT et al, 2003). Embora a produção acadêmica desenvolvida a partir da década de 1980 tenha conseguido se distanciar dessa perspectiva, ainda é comum na comunidade escolar (alunos, professores, gestores, pais etc.) a concepção de que a aula de EF é um momento mais livre do cotidiano escolar. O estudo de Loyola, Fonte e Figueiredo (2010), que abordou os sentidos atribuídos à EF por profissionais da escola, corrobora tal fato, já que evidenciou que sobre a EF pairam significações de disciplina "curinga" e/ou de menor prestígio. No estudo de Mattos (2006), que investigou as relações que professoras primárias estabeleciam com as atividades lúdico-corporais, desenvolvidas nas aulas de EF de seus alunos, há a elucidação de que as atividades das suas aulas são menos importantes do que as das outras disciplinas.

Dessa forma, não raro a EF é a disciplina preferida de grande parte dos alunos, justamente pela cristalização da ideia de menor rigidez. Entretanto, um fato é significativo: muitos alunos não se envolvem com 
as atividades propostas nas aulas de EF, encontrando-se à margem das mesmas, na "periferia da quadra". Para este estudo, o conceito de "periferia da quadra" não se limita ao espaço físico dos arredores da quadra ou seus "cantos", mas também sendo uma referência subjetiva aos tempos da aula de EF vivenciados pelos alunos que se distanciam da proposta inicial do professor. A preferência por utilizar o termo "quadra" deve-se ao estreito significado que este espaço escolar mantém com a EF.

Em trabalhos como os de Souza (2008), que estudou a representação da EF por alunos do ensino médio, Fernandes (2008), que estudou os sentidos de gênero produzidos por alunos nos dois primeiros anos iniciais do Ensino Fundamental em suas aulas de EF, Matsumoto (2009), que estudou o ensino-aprendizado do gesto em suas aulas de EF desenvolvidas na primeira fase do Ensino Fundamental e Oliveira e Daolio (2010), que estudaram a forma como os alunos lidam com as diferenças nas aulas de EF, é possível evidenciar o fenômeno da "periferia da quadra".

Assim, nos parece plausível olhar para tal fenômeno, entendendo que, ao mesmo tempo em que é comum e contraditório, não é algo dado ou natural, mas produzido pelo contexto escolar e com íntima relação com a prática pedagógica dos professores.

Dessa forma, o objetivo do estudo é analisar a relação entre a prática pedagógica em Educação Física e a produção da "periferia da quadra". Em nosso entendimento, uma análise detalhada de tal fenômeno - "periferia da quadra" - permite vislumbrarmos novos olhares para a inserção da EF no contexto escolar.

\section{PROCEDIMENTOS METODOLÓGICOS}

O método de pesquisa utilizado centrou-se na etnografia. A pesquisa de campo foi desenvolvida durante pouco mais de 6 (seis) meses (25/05/2009 à 12/12/2009) no cotidiano de uma escola pública, observando-se aulas de EF de uma turma de $7^{\circ}$ ano do ensino fundamental. Durante esse período foram observadas 32 (trinta e duas) aulas. Como instrumento de coleta de dados foi utilizado o diário de campo. Para Magnani (1996), o diário de campo situa-se na intersecção dos conceitos de "experiência-próxima" e "experiênciadistante" de Geertz (1997). Isso porque, "quando já se está 'aqui', o caderno de campo fornece o contexto de 'lá'; por outro lado, transporta de certa forma para 'lá', para o momento da experience-near, a bagagem adquirida e acumulada nos anos gastos 'aqui', isto é, na 
academia, entre os pares, no debate teórico (MAGNANI, 1996, p.1) ${ }^{1}$ Também foram feitas entrevistas com o professor de EF e com os alunos da turma. Todas as entrevistas realizadas foram do tipo semi-estruturada, que, segundo Triviños (2008), parte de certos questionamentos básicos, apoiados em pressupostos que interessam à pesquisa. De acordo com o autor, a entrevista semi-estruturada é um dos principais meios para realizar coleta de dados numa pesquisa qualitativa, ao mesmo tempo em que valoriza a presença do investigador e oferece todas as perspectivas possíveis para que o informante alcance a liberdade e a espontaneidade necessárias, enriquecendo a investigação.

Para Geertz (1997), a etnografia se parece com compreender o sentido de um provérbio, captar uma alusão, entender uma piada. Para isso, dois conceitos elucidados pelo autor são fundamentais: "experiência-próxima" e "experiência-distante". Embasado no psicanalista Heinz Kohut, o autor entende que

\begin{abstract}
Um conceito de "experiência próxima" é, mais ou menos, aquele que alguém - um paciente, um sujeito, em nosso caso um informante - usaria normalmente e sem esforço para definir aquilo que seus semelhantes vêem, sentem, pensam, imaginam etc. e que ele próprio entenderia facilmente, se outros o utilizassem da mesma maneira. Um conceito de "experiência-distante" é aquele que especialistas de qualquer tipo - um analista, um pesquisador, um etnógrafo, ou até um padre ou um ideologista - utilizam para levar a cabo seus objetivos científicos, filosóficos ou práticos. "Amor" é um conceito de experiência próxima; "catexia em um objeto" de experiência-distante. "Estratificação social" e, talvez para a maioria dos povos do mundo, "religião" (e certamente "sistema religioso") são de experiênciadistante; "casta" e "nirvana" são de experiência-próxima, pelo menos para hindus e budistas (GEERTZ, 1997, p.87, grifos do autor).
\end{abstract}

Assim, o autor propõe compatibilizar os níveis de experiência próxima e distante, uma vez que não são opostas, evitando a opção por um dos níveis e a fim de obter a aproximação necessária para a pesquisa. "Limitar-se a conceitos de experiência-próxima deixaria o etnógrafo afogado em miudezas e preso a um emaranhado vernacular. Limitarse aos de experiência-distante, por outro lado, o deixaria perdido em abstrações e sufocado com jargões" (GEERTZ, 1997, p.88).

Dessa forma é que este estudo se lança em direção à compreensão da prática pedagógica e a produção da "periferia da quadra", pressupondo que o acesso a essa relação muito tem a contribuir para o melhor entendimento desta tensa, densa e complexa teia que cerca a prática da EF escolar. 
O objetivo é tirar grandes conclusões a partir de fatos pequenos, mas densamente entrelaçados; apoiar amplas afirmativas sobre o papel da cultura na construção da vida coletiva empenhando-as exatamente em especificações complexas (GEERTZ, 1989, p.38).

No entanto, na direção que afirma Fonseca (1999), entendendo que nossas análises devem ser tratadas como hipóteses a serem "exploradas/discutidas" ao lado de outras, servindo para oferecer uma alternativa, abrindo o leque de interpretações possíveis, mas não para fechar o assunto ou criar novas fórmulas dogmáticas.

Assim, é que corroboramos o posicionamento de Silva, Velozo e Rodrigues Júnior (2008, p.58), quando afirmam que a pesquisa qualitativa em EF permite renovações à área, principalmente por permitir a interpretação dos significados que os sujeitos atribuem ao corpo, às práticas corporais e às aulas de EF, portanto "[...] mediada pelo olhar do pesquisador, e não restrita aos fatos, como se eles [os dados], por si sós, se manifestassem de maneira objetiva".Para tanto, a pesquisa foi desenvolvida numa escola de ensino fundamental da Rede Municipal de uma capital brasileira ${ }^{2}$, que denominaremos aqui de "Escola dos Sonhos". Tal denominação tem estreito vínculo com o fato de a unidade escolar ter sido considerada, em 2008, a melhor escola pública de ensino fundamental do Estado, de acordo com o Índice de desenvolvimento da Educação Básica (IDEB), bem como ser motivo de orgulho da comunidade escolar.

Em 2009, a "Escola dos Sonhos" era composta por pouco mais de 450 alunos (25 alunos por turma), 35 professores (entre efetivos e temporários) e outras 30 pessoas que compunham o quadro técnico-administrativo da escola (direção, coordenação, secretaria, caixa escolar, biblioteca, agentes de suporte operacional, serviços externos, merendeiras, vigilância e estagiários).

A "Escola dos Sonhos" funcionava dentro do espaço físico de uma universidade pública federal. Durante seus 10 (dez) primeiros anos de funcionamento, a instituição funcionou como uma unidade federal de ensino em convênio com a prefeitura. A universidade administrava o espaço físico, fomentando os recursos necessários para o funcionamento da escola, e à prefeitura cabia a lotação de professores para desenvolver o projeto pedagógico. No entanto, em 1998, a escola foi municipalizada, passando a ser uma unidade municipal de ensino. 
Em seu espaço físico, a escola comporta 12 salas de aula, biblioteca, sala de informática, 2 quadras (sendo uma coberta e outra descoberta), sala de vídeo, sala de música, sala da rádio da escola, sala onde são guardados os materiais utilizados nas aulas de EF, 5 banheiros (4 destinados aos alunos), sala da Direção, 2 salas para a Coordenação, secretaria e refeitório. Existem ainda 2 grandes espaços ao ar livre, bem arborizados: um na entrada e o outro no interior da escola.

Em relação aos sujeitos da pesquisa, estes são: o Professor João e os alunos do $7^{\circ}$ ano. ${ }^{3}$

Dentre os professores de EF, o Professor João, na época da pesquisa, era o que estava há mais tempo na escola. Chegamos até esse professor por indicação de uma coordenadora pedagógica, que justificava se tratar de um professor mais experiente. E realmente o era, já que tinha se formado em Educação Física em 1986, tendo, em 2009, 9 anos de experiência como professor na educação básica e 14 anos de experiência na área esportiva, na qual atuou em cargo administrativo, como técnico e também atleta. Além disso, parecia ter maior grau de pertencimento com aquele contexto em relação aos seus colegas, outros 3 professores recém-chegados na escola. Tal indicação soou, a priori, como um direcionamento que pudesse atrapalhar o desenvolvimento da pesquisa, o que nos fez quase descartar a hipótese de trabalhar com o professor João. No entanto, resolvemos acatar a indicação da coordenadora, nos abrindo assim a fatos não previstos, considerando o pressuposto elucidado por André (1997), a qual afirma que, em etnografia, o pesquisador deve ser flexível no trabalho de campo.

Dessa forma, se por algum motivo, a indicação do professor João poderia representar uma tentativa de direcionamento da escola para a pesquisa, por outro lado tratava-se da possibilidade de contato com um profissional mais experiente, melhor entendedor das questões do cotidiano da escola. Embora fosse um risco, no sentido de que se ele era melhor entendedor do cotidiano escolar poderia também ser um bom sonegador de informações, no sentido de não se expor, a decisão de acatar a indicação da coordenadora considerou também o fato do pertencimento e da referência que esse professor tinha perante a trama social do cotidiano escolar, sendo útil para o desenvolvimento da pesquisa.

Tendo o professor concordado com a realização da pesquisa restou selecionar a turma a ser investigada. Tal processo se deu em diálogo com o professor, que, considerando a questão 
da disponibilidade dos pesquisadores em estar na escola, chegou-se à turma do $7^{\circ}$ ano.

O $7^{\circ}$ ano era formado por 25 alunos, dos quais 15 meninos e 10 meninas com faixa-etária entre 13 e 15 anos. De acordo com o professor João, a turma só pensava na quadra, na bola, no jogo e não se interessava por outras atividades. Por isso, a turma era encarada como um desafio profissional. Segundo os próprios alunos, a turma conversava demais, era agitada.

As aulas de EF aconteciam duas vezes por semana, com duração de 50 minutos cada aula. A organização e sistematização dos conhecimentos de EF para a turma do $7^{\circ}$ ano em 2009 foram:

- $1^{\circ}$ trimestre: Conhecimentos sobre o corpo e atividade física; Futsal;

- $2^{\circ}$ trimestre: Voleibol;

- $3^{\circ}$ trimestre: Handebol.

Questionado sobre o porquê não trabalhava com os outros conteúdos da EF, o professor João afirmou que era por falta de afinidade com os mesmos. Mostrou-se preocupado com a questão, afirmando que precisava quebrar essa barreira, mas que também não iria trabalhar um conteúdo que não dominava só para dizer que trabalhou. Outro argumento centrou-se na informação dada pelo professor de que os alunos, após uma discussão aberta por ele no início do ano, manifestaram o desejo de trabalhar com o conhecimento corporal, atividades físicas e as modalidades esportivas.

Uma série de críticas poderia ser feita a partir desse dado, como por exemplo, a esportivização das aulas de EF em detrimento a outros conteúdos, limitando assim o horizonte do processo de aprendizagem dos alunos, tão bem elucidadas por Faria (2001) e Oliveira (2001). Entretanto, os limites impostos a um texto como esse restringe maior discussão, cabendo apenas uma ressalva. Pesquisas sobre a trajetória de vida de professores de EF, como a de Borges (1998), têm demonstrado que a prática pedagógica desenvolvida por esses professores nas escolas é influenciada, diretamente, por suas experiências de vida. Em Sanchotene e Molina Neto (2010), que investigaram a constituição da prática pedagógica de professores de EF numa escola em Porto Alegre, foi evidenciado que as experiências corporais vivenciadas pelos professores acabam por serem utilizadas em aulas em detrimento de outras práticas. No caso do professor João, acreditamos que sua experiência esportiva, acumulada ao longo de muitos anos, tenha sido decisiva na seleção do conteúdo em sua prática pedagógica. 


\section{AS AULAS DE EDUCAC̣ÃO FÍSICA E A PRODUC̦ÃO DA “PERIFERIA DA QUADRA"}

Em nosso trabalho de campo, o planejamento traçado para as observações das aulas consistiu, num primeiro momento, em decifrar fragmentos que pudessem fornecer quais seriam os alunos ou grupos de alunos que se encontravam na "periferia da quadra". Com os alunos mapeados e agrupados, poderíamos, num segundo momento, dedicarmos aos desdobramentos pretendidos.

No entanto, durante a realização das primeiras observações e analisando, a posteriori, o conjunto de dados registrados no diário de campo, vários foram os eventos que corroboraram o fato de que todos os alunos, em algum momento da aula, permeavam a "periferia da quadra". De acordo com Magnani (2003, p.84-85), tal fato é possível devido à forma com que a etnografia opera, em que

\footnotetext{
[...] o pesquisador entra em contato com o universo dos pesquisados e compartilha seu horizonte, não para permanecer lá ou mesmo para captar e descrever a lógica de suas representações e visão de mundo, mas para, numa relação de troca, comparar suas próprias representações e teorias com as deles e assim tentar sair com um modelo novo de entendimento ou, ao menos, com uma pista nova, não prevista anteriormente (grifos nossos).
}

Assim, reiterando a concepção elucidada anteriormente de que o termo "periferia da quadra" não significa somente os arredores físicos ou os "cantos" do espaço escolar da quadra, mas também uma referência subjetiva aos tempos da aula de EF vivenciados pelos alunos que se distanciam da proposta inicial do professor, chegamos à compreensão de que todos os alunos, em algum momento da aula, permeavam a "periferia da quadra".

Inicialmente, relacionamos o fato ao enredo da aula, chegando ao provisório entendimento de que a situação de todos na "periferia da quadra" dava-se ora por desinteresse dos alunos em relação à atividade proposta pelo professor (conteúdo), ora por desinteresse em relação à forma com que a mesma era desenvolvida (método).

Tal fato, notado inicialmente entre a $4^{\mathrm{a}}$ e $5^{\mathrm{a}}$ aula, levou-nos a um reordenamento da estratégia em campo. Assim, a tarefa inicial, que consistia em delimitar alunos ou grupos de alunos que se colocavam à margem da aula, deu lugar a um olhar mais amplo que consistiu, também, na observação do que faziam os alunos durante as aulas de EF. Além disso, outra tarefa consistiu em revisitar o diário de campo para analisar as anotações das aulas anteriores 
( $1^{\mathrm{a}}$ à $4^{\mathrm{a}}$ aula) a partir dessa nova perspectiva. De certo modo, não há como precisar se foi a observação mais geral, empenhada nos primeiros dias de observação, que levou à pista - todos se encontram à margem da aula - ou se foi a descoberta da pista que nos levou a proceder a observações mais amplas.

Após as observações realizadas, as aulas de EF do $7^{\circ}$ ano da "Escola dos Sonhos" puderam ser assim categorizadas: aulas em sala e aulas em quadra. No caso das aulas em sala, o professor explanava o conteúdo a partir de conceitos gerais. Nestas, que ocorreram em 5 (cinco) oportunidades, o professor era constantemente interrompido pelos alunos que o questionavam se iriam para a quadra naquele dia. Tal fato não permitia a fluidez da aula, consequentemente, as mesmas transcorriam num misto de desânimo, desinteresse e apatia por parte dos alunos.

Já nas aulas realizadas em quadra, nas quais tínhamos a expectativa de notar um ávido interesse dos alunos pelas atividades, todos eles, em algum momento, também esboçaram desinteresse, desânimo e apatia. Nestas, após momento inicial em sala de aula, o professor e os alunos dirigiam-se para a quadra para realizarem o previsto. Nesse contexto, João empregava, regularmente, 3 (três) métodos de trabalho: aulas diretivas, aulas de prática livre e aulas livres.

Nas aulas diretivas, o professor propunha a atividade e intervinha junto aos alunos instigando-os a pensar outras possibilidades para as ações desenvolvidas. Já nas aulas de práticas livres, a dinâmica era diferente. Nestas, o professor determinava uma tarefa e, ora à distância, ora mais perto, observava o andamento da atividade. A intervenção do professor limitava-se a algumas dicas técnicas em relação aos gestos realizados pelos alunos e à garantia da realização da atividade. No que se refere às aulas livres, a dinâmica consistia no fornecimento do material e controle do tempo nas atividades desenvolvidas. Estas, exclusivamente, giraram em torno do futebol, sendo o tempo da aula dividido para dois grupos distintos: meninos e meninas. Na espera pela vez de jogar, os grupos ocuparam o tempo de várias formas: assistindo o jogo da arquibancada, conversando com o professor, praticando futebol nos arredores da quadra, ouvindo música, dançando, ensaiando algumas brincadeiras ou, simplesmente, jogando conversa fora.

Nas aulas diretivas, a resistência pelas atividades propostas pelo professor foi evidente. Assim, dez ou quinze minutos da aula destinado, por exemplo, ao toque e manchete do voleibol, 
era considerada uma perda de tempo pelos alunos. Os que se aventuraram a cumprir as atividades, a maioria meninos, pareciam não se sentir muito à vontade em quadra. As aulas diretivas ocorreram em seis oportunidades ao longo das trinta e duas aulas observadas.

Nas aulas de prática livre, o quadro observado também foi de resistência dos alunos às atividades, consequentemente, pouco envolvimento no proposto pelo professor. Houve também inúmeras transgressões ao conteúdo e a forma como as aulas foram pensadas inicialmente e, como consequência, vários alunos sentados nas arquibancadas.

Nas aulas livres, como já informado anteriormente, o futebol predominou. Entretanto, uma observação é pertinente: apesar de o futebol ter sido contemplado como conteúdo do primeiro trimestre, o mesmo figurou como prática predominante nas aulas de EF do segundo e terceiro trimestres do $7^{\circ}$ ano em dez oportunidades, sem contar os minutos iniciais de todas as aulas na quadra precedidas por ensaios "futebolescos" com tampinhas, garrafas, bolinhas de papel, bolas de qualquer esporte ou qualquer outro material que pudesse ser chutado. Ou seja, apesar da sistematização ter previsto o desenvolvimento dos conteúdos de voleibol e handebol, o futebol foi uma prática privilegiada, tomando quase dois terços do tempo letivo previsto. Ressaltamos que o fenômeno das aulas livres é muito comum nas aulas de EF. Em Fortes et al. (2012), que estudaram o contexto das aulas de EF na cidade de Pelotas-RS, foi observado que metade das aulas de EF do Ensino Fundamental e 40\% das aulas do Ensino Médio adotam essa prática.

Em outras seis aulas observadas, que não se encaixaram nas categorias descritas neste estudo, devido à sua atipicidade, houveram as seguintes dinâmicas:

- Uma aula destinada à avaliação escrita ;

- Uma aula destinada à comemoração do aniversário de uma aluna (um pedido dos próprios alunos);

- Uma aula na qual o professor dialogou com os alunos sobre a falta de comprometimento destes com os estudos;

- Uma aula na qual o professor divulgou os resultados finais (notas) da disciplina e fez um balanço do ano letivo, finalizando com um jogo de queimada na quadra, atividade da qual também participou;

- Duas aulas nas quais o professor esteve ausente. ${ }^{4}$ 
Assim, numa primeira análise, podemos corroborar a afirmação feita anteriormente de que a situação de todos na "periferia da quadra" deu-se ora por desinteresse dos alunos em relação à atividade proposta (conteúdo), ora por desinteresse em relação à forma com que a mesma era desenvolvida (método).

Entretanto, entendemos que, para além do conteúdo esportivo proposto pelo professor, com privilégio à prática do futebol, o método não-diretivo de sua prática pedagógica foi fator relevante para a existência da "periferia da quadra". Isso porque, ao priorizar as aulas de prática livre e as aulas livres, que, somadas aconteceram em quinze oportunidades, João deixou nas mãos dos alunos decisões pedagógicas que, minimamente, deveriam ser compartilhadas.

A justificativa do professor para essa conduta pedagógica teve como ponto central o que ele concebia como sendo os objetivos da EF na escola.

\footnotetext{
Nós, dentro da Rede Municipal, criamos - como eu chamaria - um currículo, algumas diretrizes [o professor ficou de disponibilizar o documento, mas não o fez] [...] Assim criamos algumas ações para trabalhar como professores, como grupo da educação física dentro da Rede. E dentro dessas atividades nós enfatizamos muito a questão da socialização dos alunos, da descoberta da participação, da parceria, da amizade, do carisma e da segurança, autoafirmação deles enquanto seres, enquanto pessoas. E a gente tem levantado essas discussões dentro da sala de aula, dentro das escolas (Professor João).
}

Ou seja, mais importava se esses objetivos eram alcançados do que os conteúdos ministrados. O conteúdo se transformava no meio pelo qual se acessava outras coisas, sendo eles facilitadores do processo educacional. Outra questão, igualmente pertinente, é que, para o professor, tal conduta pedagógica faria com que os alunos tivessem acesso a uma prática ressignificada do esporte. Segundo ele, a maior liberdade dada aos alunos nas aulas facilitaria o acesso às novas formas de criação e recriação do esporte, em detrimento aos modelos pré-existentes.

Nessa esteira, pouco importa o que se faz, mas como se faz, ou, dito de outra forma, o método torna-se mais relevante que o conteúdo desenvolvido. Tal perspectiva se aproxima da ideia de não-diretividade desenvolvida em Snyders (1978). Para este autor, as teorias da não-diretividade vieram combater o rígido modelo educacional centrado na dominação do professor sobre o aluno e a fraqueza passiva deste frente ao processo educacional. Assim, o autor acredita que o advento da não-diretividade contribuiu 
de forma significativa para o repensar dos processos educativos frente à maior autonomia e liberdade dos alunos. Snyders afirma que, embora não seja possível definir a não-diretividade, a mesma se traduz em possibilitar aos alunos uma vivência democrática de turma/classe, na qual os mesmos são chamados a participar ativamente do processo, não sendo exclusivas do professor as tomadas de decisões. Para isso, essas precisam ser compartilhadas por todos, não devendo haver nenhum tipo de coação por parte do professor.

Em torno dessa premissa, Snyders se propôs a analisar algumas obras $^{5}$ que buscavam tal caminho, mesmo entendendo que alguns autores analisados não concordariam com suas considerações e nem com o rótulo de não-diretivista. Dessa forma, o livro "Para onde vão as pedagogias não-directivas?" encontra-se dividido em duas partes. $\mathrm{Na}$ primeira o autor procede à análise de algumas obras, buscando caracterizar a não-diretividade presente em cada teoria, bem como elucida a fragilidade que estas trazem para o campo da educação. $\mathrm{Na}$ segunda parte, Snyders busca argumentar em direção a uma pedagogia progressista, entendendo o marxismo como única via capaz de superar as fragilidades da não-diretividade. Embora este estudo não compartilhe o mesmo horizonte teórico (marxismo) de Snyders, acreditamos que as considerações do mesmo em relação à não-diretividade muito têm a contribuir para o entendimento da prática pedagógica de João.

Para Snyders, apesar do advento da não-diretividade ter contribuído para a revisão do caráter autoritário da prática pedagógica tradicional, o receio é de que este esforço em prol de uma maior autonomia e liberdade para os alunos possa se traduzir em alguns reducionismos. Nas palavras de Snyders (1978, p.8), o receio é

[...] que a abdicação do mestre deixe os alunos serem vítimas de estereótipos estabelecidos, que uma certa indiferença pelos conteúdos do ensino e pela sua força de verdade condene os alunos a um cepticismo inevitavelmente passivo e, no fim de contas, os deixe desarmados perante as tarefas de envergadura que deveriam empreender [...] receamos que a não-directividade, apesar das aparências paradoxais, não consiga dar liberdade bastante ao aluno, autonomia bastante à classe; receamos que seja infinitamente menos revolucionária do que julga ser [...] (grifo nosso).

Mas por que Snyders fala em abdicação do mestre? Porque um ponto comum entre todas as teorias e/ou pedagogias nãodiretivas analisadas por ele, tem como prerrogativa uma parcial ou total ausência do professor no decorrer da prática pedagógica, 
pois o professor precisa deixar de existir como autoridade, no máximo oferecer um auxílio quando solicitado. Isso para que não seja usurpada a liberdade dos alunos.

$\mathrm{Na}$ pior das hipóteses não-diretivistas, o professor é apenas um vigilante das atividades dos alunos, não toma partido de ninguém e de nenhum grupo e, em nome da maior autonomia e liberdade dos alunos, pode, no máximo, fornecer algumas pistas breves. É preciso que os próprios alunos encontrem suas respostas. E na melhor das hipóteses não-diretivistas, o professor é uma espécie de coordenador das atividades, um líder democrático que, diante de qualquer problema, convoca uma discussão para que o grupo possa resolver coletivamente e consensualmente a questão. Nessa perspectiva, o professor garante VOZ a todas as partes, não permitindo nenhum tipo de coação, muito menos de sua parte.

Entretanto, a preocupação dos não-diretivistas com a liberdade e autonomia dos alunos se afunda no conformismo social, pois na ausência de uma intervenção docente que possibilite ao aluno galgar novos horizontes de conhecimento, os mesmos recorrerão a outras influências. Para Snyders (1978, p.273), recorrendo a Oury, “[...] onde falta uma estrutura muito firme, instituída e mantida pelo adulto, não surge qualquer libertação e cada um continua prisioneiro da rotina e do conservantismo" . Dessa forma, compartilhamos a mesma compreensão de Snyders, que se traduz no receio de que a não-diretividade não consiga resolver os problemas denunciados.

Assim, entendemos que a não-diretividade encontrou eco na prática pedagógica do professor João. A ideia de uma aula mais livre em que os alunos decidissem os rumos de suas aprendizagens acabava por contemplar o que ele intencionava combater, a reprodução irrefletida do esporte nas suas aulas. Ao deixar na mão dos alunos a maior parte ou todas as decisões de uma aula, como no caso das aulas livres e das práticas livres, o modelo a ser combatido predominava, contribuindo para a existência da "periferia da quadra". Kunz (1994), ao se pronunciar sobre os princípios do esporte profissional, enfatiza que os mesmos estão alicerçados na sobrepujança e nas comparações objetivas, gerando vivências de sucesso para uma minoria e de insucesso para uma grande maioria. Fatos que, mesmo não sendo intencionados por João, ressoaram no $7^{\circ}$ ano, levando à recorrência da "periferia da quadra".

Dessa forma, passamos a entender que a "periferia da quadra", para além de uma referência subjetiva aos tempos da aula de EF vivenciados pelos alunos que se distanciavam da proposta 
inicial do professor, como já exposto, também traduziu os tempos da aula de EF vivenciados pelos alunos que resultaram da proposta inicial do professor. Isso porque, a não participação de alguns alunos, que preferiram sentar-se nas arquibancadas, ouvir música, dançar, rir dos colegas ou participar sem muito interesse na atividade, também foi fruto da intervenção do professor perante a turma, deixando-a "livre" para desenvolver suas ações, entendendo que desta forma, sem imposições, os alunos poderiam chegar à transformação do esporte e não à sua reprodução, o que não ocorreu.

Entretanto, apesar de toda a contextualização feita até o momento do que seja a "não-diretividade", faz-senecessário ressaltar que a mesma não significa ausência de diretividade ou deintervenção. Pelo contrário, é um tipo de intervenção, um tipo de diretividade. Isso porque, em qualquer prática pedagógica a diretividade está presente de diferentes formas. Dessa forma, uma prática pedagógica não-diretiva, em consonância com Snyders (1978), minimamente, traduz uma intervenção na qual o professor interfere pouco na conduta dos alunos, deixando para estes algumas decisões que lhes caberiam.

Para Snyders (1978, p.227-228), embasado em Lobrot, se deixam os alunos imersos em suas próprias iniciativas e/ou necessidades "[...] é absolutamente irreal pensar que os seus interesses vão coincidir com as tarefas escolares e, miraculosamente, ao encontro das exigências do programa escolar". Ou seja, as aulas livres e práticas livres, contidas na prática pedagógica do professor João, dificilmente se materializariam numa prática esportiva ressignificada, como queria o mesmo. Para isso, seria necessário que desenvolvesse sua intervenção no sentido de levar os alunos a explorar universos diferentes de conhecimento, ou mesmo explorando outros conhecimentos que não só o Futebol, Voleibol e Handebol. Para Kunz (1994), que expôs e defendeu uma pedagogia crítico-emancipatória para a transformação didático-pedagógica do esporte, uma prática pedagógica capaz de levar o aluno a ampliar seu horizonte de conhecimento necessita considerar três dimensões:

1. Trabalho: desenvolvimento da competência objetiva. Para Kunz (1994), o aluno precisa receber conhecimentos e informações e treinar destrezas técnicas (Saber Fazer);

2. Interação: desenvolvimento da competência social. Aqui, o autor entende que o aluno deve adquirir informações sobre as relações socioculturais do contexto que ele vive. 
No caso do esporte, especificamente, superar as desigualdades de gênero (Saber Interagir);

3. Linguagem: desenvolvimento da competência comunicativa. Nesta dimensão, Kunz afirma que, ao aluno, deve ser dada a oportunidade de se comunicar e entender a comunicação do outro. Entretanto, não só a comunicação corporal, através dos gestos técnicos, mas, acima, de tudo, discursar sobre o aprendido e vivenciado (Saber Comunicar).

Considerando o contexto observado, percebeu-se que nenhuma dessas três dimensões foi desenvolvida pelo professor João com a turma do $7^{\circ}$ ano. A nosso ver, tal fato também favoreceu a existência da "periferia da quadra".

Outra questão foi que, para os alunos, apesar das aulas livres serem muito interessantes, pois podiam desenvolver o que desejassem, a não-diretividade do professor era uma queixa. Até certo ponto, pode-se entender tal consideração como contradição, pois a não-diretividade proporcionava maior liberdade aos mesmos nas aulas. Entretanto, a falta da mesma também resultava na "periferia da quadra", igualmente não interessante para eles.

Ele podia dar atividades mais diversificadas (Antônia - aluna do $7^{\circ}$ ano).

Um dia na sala, com regras e fundamentos, e outro na quadra, para aplicação do que foi visto em sala (Fábio, aluno do $7^{\circ}$ ano).

Em todas as entrevistas realizadas com os alunos, foi possível elucidar que os mesmos gostariam de ter aulas diferentes, nas quais o professor propusesse conteúdos diversificados e desenvolvesse as aulas a partir de uma metodologia diferenciada, distante do que ocorria. Resumindo, faltou a oportunidade de aprendizado aos alunos, uma vez que a maior liberdade dada pelo professor não proporcionava aos mesmos expandirem seus horizontes de conhecimento, ou, como afirma Forquin (1993), estar na presença de certos elementos da cultura a fim de que deles se nutra.

Entretanto, para o Professor João, a socialização, a parceria e a amizade enfatizadas nos objetivos pedagógicos eram mais importantes do que os conteúdos ministrados. Dessa forma, chega-se a outro reducionismo característico da não-diretividade, também discutida por Snyders (1978): a indiferença aos conteúdos do ensino. Ou seja, na não-diretividade há maior 
valorização da vivência em grupo do quea aprendizagem dos conteúdos. "Não se faz mais nada senão falar em método, parece que tudo se joga sobre a oposição entre métodos, autoritários, liberais, concentrados no grupo, etc" (SNYDERS, 1978, p.310).

Para Snyders (1978), enfocar todos os problemas educacionais na vida em grupo, entre professores e alunos, é permitir o entendimento de que, no processo ensino-aprendizagem, apenas as ligações entre os grupos têm importância. E os conteúdos de ensino, em que pé se situam? Nesse sentido é que, mais uma vez, a não-diretividade se pronunciou na prática do professor João, pois, ao deixar claro que o conteúdo esportivo é o meio pelo qual se acessa o objetivo desejável da EF, a socialização, torna-se nítida a indiferença aos conteúdos de ensino. Ora, não deveria ser o oposto: a socialização, a parceria e a amizade é que deveriam ser caminhos facilitadores para se atingir a aprendizagem dos conteúdos? Pensar e propor relações menos autoritárias entre professores e alunos é imprescindível e desejável para a escola, mas não se deve entender a mesma como única responsável pela revolução educacional. Os conteúdos também devem ser levados em conta nesse processo. E este foi um ponto secundário na prática de João. Primeiramente, porque os conteúdos não eram diversificados e não havia intenção em modificá-los. Segundo, porque os conteúdos eram apenas formas pelas quais se atingiam outras coisas: o velho e incansável discurso do esporte como agente facilitador de socialização.

Nessa perspectiva, para Snyders (1978, p.122-123) 'está ausente a idéia de uma escola que suscita, elabora, afina as necessidades, ajuda a desabrochar necessidades novas". Em Oliveira (2012), o qual relata a experiência de felicidade e encantamento de uma aluna do ensino fundamental por ter aprendido um movimento corporal novo, há a afirmação de que a prática pedagógica necessita apresentar algo novo ao aluno e este precisa se esforçar para aprender, não simplesmente contemplar a existência do referido conhecimento. Nesse mesmo exemplo, para que a aluna aprendesse "[...] foram necessárias algumas esforçadas tentativas, impostas pelo professor e, posteriormente, desenvolvida com mais liberdade pela aluna (OLIVEIRA, 2012, p.67). Entretanto, tal perspectiva esteve distante das aulas de EF do $7^{\circ}$ ano da "Escola dos Sonhos". Para José, aluno do $7^{\circ}$ ano, as aulas de EF deveriam ter mais conteúdo. Quando perguntado se as aulas de EF eram boas, o mesmo respondeu: 
Em questão de conteúdo, nem tanto, porque é só futebol. E nem tem algo de futebol, ele dá a bola e a gente fica aqui.

Ou seja, a simples presença do professor não garante aprendizagem. Em geral, os alunos possuem limites que não superam por si mesmos, ou na simples convivência com seus pares, é preciso que haja uma intervenção que mexa com as estruturas postas. "O novo não surge do nada; consiste em aprofundar, mesmo modificando-o completamente, o que já tinha sido obtido" (SNYDERS, 1978, p.122).

Para Paulo Freire (1997), a prática da liberdade fundamentase na educação do desejo: fazer com que os alunos ampliem seus desejos e/ou conheça-os melhor. Desejo de jogar futebol, dançar, fazer cestas etc. Nas palavras do próprio Freire: saber melhor o que já sabemos e saber o que não sabemos. Assim,

Se trabalho com crianças, devo estar atento à difícil passagem ou caminhada da heteronomia para a autonomia, atento à responsabilidade de minha presença[como professor] que tanto pode ser auxiliadora como pode virar perturbadora da busca inquieta dos educandos; se trabalho com jovens ou adultos, não menos atento devo estar com relação a que o meu trabalho possa significar como estímulo ou não à ruptura necessária com algo defeituosamente assentado e à espera de superação (FREIRE, 2002, p.78). ${ }^{6}$

Para isso, não deve haver omissão por parte do professor. Omissão de autoridade, omissão de se perceber como um sujeito formador, muito menos omissão de conteúdo, pois é, também, através deste que os educandos podem transformar o mundo em que vivem e/ou praticar a liberdade de vivê-lo de forma mais autônoma. "Crescer é precisamente, para a criança [educando], apropriar-se da riqueza social, participar do patrimônio cultural" (SNYDERS, 1978, p.333).

Tal processo potencializa para o que Snyders (1997), em outro texto, nos chama a atenção: as alegrias da escola. O autor, referindose ao processo de tocar e cantar, afirma que há um prazer evidente sobre a atividade musical. Entretanto, o mesmo chama a atenção para o fato de que o progresso na atividade não acontece automaticamente, pelo contrário, exige um trabalho árduo de aprendizagem. Ou seja, não existe aprendizagem, muito menos na EF escolar, sem um investimento do professor, no mínimo, na instrumentalização do aluno, sendo esta outra prerrogativa que esteve distante das aulas de 
EF do $7^{\circ}$ ano. Isso porque, de acordo com Snyders (1978), quando não há orientação por parte do educador, o lugar fica disponível para uma amálgama de influências difusas.

E foi em meio a esses embaraços que a "periferia da quadra" configurou-se como tempo e espaço de vivências diversas e contraditórias dos alunos em torno das práticas corporais proporcionadas nas aulas de EF. Sendo esse movimento consequência de uma prática pedagógica não-diretiva do professor João em suas aulas de EF.

\section{CONSIDERACְÕES FINAIS}

Ao investigar a relação entre a prática pedagógica em Educação Física e a produção da "periferia da quadra", buscamos evidenciar algumas minúcias que acabaram por corroborar e ampliar o entendimento de que a "periferia da quadra" não é algo dado ou natural, mas produzido pelo contexto escolar.

Neste estudo, a produção de uma"periferia da quadra" esteve intimamente relacionada à prática pedagógica não-diretiva do professor de EF, que, ao aspirar maior liberdade aos seus alunos no processo educacional, acabou por levá-los ao conformismo. Dessa forma, professor e alunos mergulharam num "mais do mesmo".

Percebemos que a "periferia da quadra" é um fenômeno extremamente limitante do processo pedagógico. Isso porque, não é desejável que haja, num processo de ensino-aprendizagem, aproximações com o conteúdo a partir de escolhas livres dos alunos, muito menos que essas escolhas livres aconteçam mediante um leque restrito de conhecimentos - o esporte, no caso desta pesquisa. Igualmente não desejável é a ênfase nos processos de vivência em grupo, tendo como objetivo a socialização do aluno, a descoberta da parceria, da amizade e outros aspectos que privilegiam mais a convivência entre os pares do que os conteúdos. Isso não significa que não deva haver preocupação docente com as relações sociais travadas na turma, mas que não se pense que esse é o único aspecto a ser enfocado numa prática pedagógica.

Advogar maior liberdade aos alunos nas aulas não se restringe a deixá-los livres para desempenhar o que desejam, pelo contrário. "As iniciativas tomadas pelo professor tornam-se condições da própria liberdade da criança" (SNYDERS, 1978, p.255). Entretanto, não defendemos uma pura e simples centralidade nos conteúdos, 
pois há o risco de desenvolvê-los imersos em métodos autoritários ou simplesmente técnicos. Há de se instrumentalizar os alunos na direção do conhecimento, sim, mas balizados por métodos que os permitam uma constante desestabilidade, possibilitando assim, saltos qualitativos que vislumbrem uma apropriação mais ampla e complexa do conhecimento. Dessa forma, pode-se entender a prática pedagógica como outra forma de coerção sobre o aluno. Mas não uma coerção que se insere no horizonte da alienação, mas no exercício da autonomia.

Kunz (1994, p.115-116) corrobora essa perspectiva, ao se pronunciar sobre uma educação crítico-emancipatória.

[...] o ensino pela libertação destas falsas visões de mundo, falsas convicções em relação ao sentido das objetivações culturais que o jovem se defronta, pela Educação Crítico-Emancipatória, é um ensino de uma certa [sic] coerção por parte do professor e do conteúdo de ensino. Este processo de libertação deve, a princípio, ser coercitivo, pois existe uma coerção que é auto-imposta e que nos jovens se origina das influências na formação de subjetividade pela indústria cultural e meios de comunicação de massa em especial [...]

Para uma superação, somente uma contrapressão por um sistema que ainda tem este poder de exercer um papel de poder maior para a libertação: a escola. ${ }^{7}$

Isso não significa que os professores devam ser autoritários, não carinhosos com os alunos, não preocupados com os anseios destes e, muito menos, desrespeitosos com os conhecimentos prévios que estes trazem para a escola. Intervir nessa linha seria igualmente prejudicial ao desenvolvimento das crianças, adolescentes, jovens e adultos que se encontram na escola como ávidos aprendizes. A ideia centra-se no pressuposto de que, para o exercício da autonomia, é desejável que os alunos estejam instrumentalizados para exercê-la.

Por isso, compreendemos a prática pedagógica não-diretiva do professor João como fator relevante na produção da "periferia da quadra". Ao se abdicar da intervenção ou minimizá-la, esperando que a maior liberdade dada aos alunos nas aulas pudesse levá-los a uma prática ressignificada de EF, o professor abriu caminho para a cristalização e legitimação de uma aula de EF que há tempos tem sofrido críticas.

Entretanto, isso não significa uma culpabilização exclusivamente do docente para a existência da "periferia da quadra". Sabe-se que a EF é uma das poucas disciplinas, para não dizer a única, que dispõe de uma estrutura externa à sala de aula pensada para suas atividades pedagógicas, a quadra. ${ }^{8}$ Em razão disso, parece haver maior flexibilidade na prática de EF do que em qualquer outra disciplina, isso porque, de acordo com 
Dayrell (1996), nenhum local, além da sala de aula, é pensado para as atividades pedagógicas (das outras disciplinas).

Dessa forma, acabamos por visualizar também que a "periferia da quadra" se configurava como a extensão dos tempos menos rígidos da escola, como o recreio e a entrada dos alunos, caracterizada por um contato direto e livre com os colegas. Livre de uma sala de aula com mesas e cadeiras que, no máximo, permitem a relação com três ou quatro colegas; de quatro paredes e uma lousa que direcionam a atenção apenas para um lugare da relação com o professor de forma centralizada e vertical, uma vez que a maior parte do tempo passado em sala de aula os alunos estão sentados em fileiras e os professores em pé ministrando a aula à frente da sala.

Ou seja, um momento particular do aluno em que há a possibilidade de viver outras relações na escola, que não aquelas moldadas pela rotina dos livros, cálculos, lições etc. Tal momento pode ser entendido como um "pedaço", na direção dos estudos de Magnani $(1984,2002)$. Para o autor, o "pedaço" é uma categoria de análise da dinâmica cultural urbana, o qual compreende o entendimento de um espaço - ou segmento dele -, que, “[...] assim demarcado torna-se ponto de referência para distinguir determinado grupo de frequentadores como pertencentes a uma rede de relações [...]” (MAGNANI, 2002, p.21). Assim, a noção de pedaço “[...] supõe uma referência espacial, a presença regular de seus membros e um código de reconhecimento e comunicação entre eles" (p.20).

Assim, se no plano da cultura urbana, Magnani $(1984,2002)$ afirma que "pedaço" designa o espaço intermediário entre a rua e a casa, onde se desenvolve uma sociabilidade básica, neste estudo a "periferia da quadra" configurou-se como um "pedaço" situado entre os ditames escolares e o convívio social mais amplo do aluno na escola, constituindo um tempo e espaço de fuga da rigidez escolar (notas, estudo, futuro, emprego, faculdade, melhor escola do estado etc.), de legitimação da compreensão da EF como um momento menos rígido do cotidiano escolar.

Dessa forma, a "periferia da quadra" configura-se também como um tempo e espaço da aula de EF que permite aos alunos uma vivência mais ampla do que a rígida e dura rotina de ensino-aprendizagem possibilitada pelas outras disciplinas. Se para Gusmão (2003), a escola é o espaço do encontro e desencontro, buscas e perdas, descobertas e encobrimentos, vida e negação da vida, é a "periferia da quadra" que permite a dimensão do encontro, da busca, das descobertas e da vida, sendo isso o que move o interesse 
dos alunos pela aula de EF e não a manchete, o saque, o toque, o jogo de voleibol, o vídeo, a prova, o trabalho de casa, o jogo de handebol ou o elucidar de algumas regras, mesmo havendo, por parte dos alunos, um anseio por uma aula diretiva.

Assim, a EF, para além de componente curricular responsável pela sistematização e tematização dos conhecimentos da cultura corporal, torna-se também tempo e espaço para que os alunos se comuniquem livremente, conversem, troquem ideias, compartilhem afinidades, confrontem-se, mesmo que seja pelas beiradas, na "periferia da quadra".

Para além disso, sabe-se também da burocratização do trabalho docente, do escasso tempo de planejamento coletivo, dos problemas da formação continuada, da grande quantidade de aulas dadas e, porque não dizer, da baixa remuneração, que praticamente obriga os professores a jornadas duplas. Sem mencionar o desgaste profissional com o debate interno entre os pares, que, na escola observada, embora fosse uma instituição de referido destaque na comunidade, opunha concepções diferenciadas do que seria uma escola pública. Assim, tem-se uma estrutura limitante de ação pedagógica. Entretanto, esses são fatores que podem ser melhor explorados em outros futuros textos, haja vista que optamos por nos dedicar àquilo que nos pareceu mais relevante para a produção da "periferia da quadra": a prática pedagógica não-diretiva do professor de $\mathrm{EF}$.

Por isso mesmo, entendemos que não se pode, em nome da limitação escolar, haver uma prática pedagógica não atenta à aprendizagem dos alunos. É pela ação da comunidade escolar e das políticas públicas, juntamente com a iniciativa do professor, que reside a possibilidade de uma prática pedagógica ressignificada, a qual permite aos alunos serem mais autônomos frente aos desafios impostos pela escola e pelo mundo à sua volta. A partir dessa perspectiva, podemos entender que a escola pode contribuir para a formação de um cidadão mais crítico, mais autônomo e mais consciente de suas múltiplas possibilidades de inserção sociocultural, à medida que se encontra instrumentalizado para isso.

Nessa esteira, não há o entendimento de uma escola que seja fácil. A escola é difícil, pois “[...] os alunos não poderiam obter sucesso por suas próprias forças; é preciso para isso a obrigação, a orientação, a intervenção do professor" (SNYDERS, 1988, p.211). Por isso, é que a satisfação do aluno não pode se limitar apenas quando é dada a ele a oportunidade de fazer o que se quer, mas levá-lo ao encontro da satisfação em aprender. 
Assim, a produção de uma "periferia da quadra" nos alerta para a necessidade de repensarmos a participação e apropriação dos alunos nas aulas de EF. Do contrário, os reducionismos elucidados neste estudo ameaçam toda e qualquer ação pedagógica.

\section{REFERÊNCIAS}

BORGES, C.M.F. O professor de Educação Física e a construção do saber. Campinas: Papirus, 1998. BRACHT, V. et al. Pesquisa em ação: educação física na escola. Ijuí: Unijuí, 2003.

DAYRELL, J. A escola como espaço sócio-cultural. In: . (Org.). Múltiplos olhares sobre educação e cultura. Belo Horizonte: UFMG, 1996. p.136-161.

FARIA, E.L. O esporte nas aulas de educação física. Presença Pedagógica. Belo Horizonte, v.7, n.41, p.19-31, set./out., 2001.

FERNANDES, S. C. Os sentidos de gênero nas aulas de Educação Física. 2008. 116f. Dissertação (Mestrado em Educação Física)-Faculdade de Educação Física. Universidade Estadual de Campinas, Campinas, 2008.

FONSECA, C. Quando cada caso NÃO é um caso: pesquisa etnográfica e educação. Revista Brasileira de Educação, Rio de Janeiro, n.10, p.58-78, jan./abr., 1999.

FORQUIN, J.C. Escola e cultura: as bases sociais e epistemológicas do conhecimento escolar. Porto Alegre: Artmed, 1993.

FORTES, M.O.; AZEVEDO, M.R.; KREMER, M.M.; HALLAL, P.C. A educação física escolar na cidade de Pelotas-RS: contexto das aulas e conteúdos. Revista de Educação Física da UEM, Maringá, v.23, n.1, p.69-78, mar., 2012.

FREIRE, P. Ética e educação. Palestra proferida na Escola Americana em São Paulo (gravação em vídeo), 1997.

Pedagogia da autonomia: saberes necessários à prática educativa. 24.ed. São Paulo: Paz

e Terra, 2002.

GEERTZ, C. A interpretação das culturas. Rio de Janeiro: Guanabara Koogan, 1989.

. O saber local: novos ensaios em antropologia interpretativa. Petrópolis: Vozes, 1997.

GUSMÃO, N.M.M. de. Os desafios da diversidade na escola. In:

cultura e educação: olhares cruzados. São Paulo: Biruta, 2003, p.83-106. . (Org.) Diversidade,

KUNZ, E. Transformação didático-pedagógica do esporte. Ijuí: Unijuí, 1994.

LOYOLA, R.C.; FONTE, S.S.D.; FIGUEIREDO, Z.C.C. Experiências profissionais e os sentidos atribuídos à educação física em contexto escolar. Movimento, Porto Alegre, v.17, n.1, p.177-193, jan./mar., 2010.

MAGNANI, J.G.C. Festa no pedaço: cultura popular e lazer na cidade. São Paulo: Brasiliense, 1984.

O (velho e bom) caderno de campo. NAU - Núcleo de Antropologia Urbana da USP. São Paulo, p.1-1, nov., 1996. Disponível em: http://www.n-a-u.org/Magnanicadernodecampo. html. Acesso em: 27 mar. 2010.

De perto e de dentro: notas para uma antropologia urbana. Revista Brasileira de Ciências Sociais, v.17, n.49, p. 11-29, jun., 2002.

A antropologia urbana e os desafios da metrópole. Tempo social, São Paulo, v.15, n.1, p.81-95, abr., 2003.

MATSUMOTO, M.H. O ensino-aprendizado do gesto na aula de Educação Física. 2009. $211 \mathrm{f}$. Dissertação (Mestrado em Educação)-Faculdade de Educação. Universidade Estadual de Campinas, Campinas, 2009. 
MATTOS, L.O.N. Professoras primárias $x$ atividades lúdico-corporais: esse jogo vai para a prorrogação. Campinas: Autores Associados, 2006.

OLIVEIRA, R.C. Educação Física, diretividade pedagógica e a prática da liberdade. Impulso, Piracicaba, v.22, n.53, p.63-71, jan./abr., 2012.

OLIVEIRA, R.C.; DAOLIO, J. Educação física, escola e cultura: da diferença como desigualdade à alteridade como possibilidade. Movimento, Porto Alegre, v.16, n.1, p.149-167, jan./mar., 2010.

OLIVEIRA, S.A. Reinventando o esporte: possibilidades da prática pedagógica. Campinas: Autores Associados, 2001.

SANCHOTENE, M.U.; MOLINA NETO, V. Práticas pedagógicas: entre a reprodução e a reflexão. Revista Brasileira de Ciências do Esporte, Campinas, v31, n.3, p.59-78, maio, 2010.

SILVA, C.L.; VELOZO, E.L.; RODRIGUES JÚNIOR, J.C. Pesquisa qualitativa em Educação Física: possibilidades de construção de conhecimento a partir do referencial cultural. Educação em Revista, Belo Horizonte, s/v, n.48, p.37-60, dez., 2008.

SNYDERS, G. Para onde vão as pedagogias não-directivas? 2.ed. Lisboa: Moraes editores, 1978. - A escola pode ensinar as alegrias da música? Tradução: Maria José do Amaral Ferreira.

3.ed. São Paulo: Cortez, 1997.

SOUZA, A.S. Educação física no ensino médio: representações dos alunos. 2008. 148f. Tese (Doutorado em Educação Física). Faculdade de Educação Física, Universidade Estadual de Campinas, Campinas, 2008.

TRIVIÑOS, A.N.S. Introdução à pesquisa em ciências sociais: a pesquisa qualitativa em educação. São Paulo: Atlas, 1987.

\section{NOTAS}

${ }^{1}$ Grifos do autor.

${ }^{2}$ Para que seja preservado o anonimato do campo de pesquisa não identificaremos o município, uma vez que se trata de uma unidade escolar com características singulares. Pelo mesmo motivo, utilizaremos pseudônimos todas às vezes que houver referência a algum sujeito da pesquisa.

${ }^{3}$ A opção por uma turma do Ensino Fundamental II deu-se pelo argumento de que as turmas que se encontram nesse nível de ensino, estando há mais tempo na educação escolarizada, possam fornecer dados mais consistentes em relação aos objetivos da pesquisa. A não opção pelo ensino médio deu-se pelo entendimento de que fatores como vestibular e trabalho (emprego), comumente presentes ao final da escolarização, pudessem comprometer a investigação.

${ }^{4} \mathrm{Na}$ primeira falta do professor, a coordenação da escola pediu-nos que desenvolvêssemos alguma atividade com os alunos. O motivo de aceitarmos o convite foi inspirado na experiência de Geertz (1989), que, em situação inusitada (correr da polícia com os nativos) quando recém-chegado para estudar como antropólogo numa aldeia balinesa, o conferiu status de "estranho", já que até o momento sua condição era de não-existência, semelhante nossa relação com os alunos da "Escola dos Sonhos" no início da pesquisa de campo. Assim, entendemos na ocasião, se tratar de uma oportunidade importante de aproximação com os alunos, o que se mostrou válida para o decorrer da pesquisa. Já na segunda falta deJoão, a escola destinou um professor para desenvolver uma atividade com os alunos.

5 "Psychologie dynamique" - Kurt Lewin; "Libres enfants de Summerhill" - A.S. Neill; "Dynamique des groupes et éducation. Le group-classe" - Banye e Johnson; "Pédagogie de groupe" - Irving Rogers e Kaile Barrington; "Psychotérapie et relations humaines" Irving Rogers; "La pratique du travail en groupe" - Gilles Ferry; "La liberté d'apprendre. 
Justification d'un enseignement non-directif" - Daniel Hameline e Marie-Joelle Dardelin; "Du savoir et des Hommes" - Daniel Hameline; "Pédagogie institutionnelle" - Michel Lobrot e; "De la classe cooperative à la pédagogie institutionnelle" - Fernando Oury e Mlle Vasquez. Segundo o autor, "O conjunto organiza-se segundo um crescendo: em primeiro lugar, o irmão mais velho que ajuda com os seus conselhos, sem nunca impor a autoridade; em seguida Rogers, o terapeuta presente e que se esforça por não influenciar mais do que um ausente; finalmente, aqueles que desejam agir pela própria ausência, pela abdicação. Politicamente, este crescendo vai da democracia 'liberal' à moda americana (Lewin) até às utopias anarquizantes (Lobrot); e, no plano epistemológico, duma certa desconfiança céptica a respeito da verdade, até às inspiradas angústias de Kierkegaard e à recusa de que haja uma verdade, de que o absoluto possa deixar-se atingir pelo homem (Hameline e Dardelin)" (SNYDERS, 1978, p.18).

${ }^{6}$ Grifos do autor.

${ }^{7}$ Grifos nossos.

${ }^{8}$ Apesar da existência de anfiteatros, laboratórios de informática, bibliotecas, videotecas e outros espaços externos à sala de aula, incomuns na maioria das escolas públicas, estes parecem não guardar estreita relação com uma disciplina específica quanto à quadra estabelece com a EF.

Recebido: 06/06/2013

Aprovado: 29/03/2014

Contato:

Universidade Federal de São Paulo, Campus Baixada Santista Departamento de Ciências do Movimento Humano. Rua Silva Jardim, 136 Vila Mathias Santos | SP | Brasil

CEP 11015-020 